\title{
Metabolomics characterization of colostrum in three sow breeds and its influences on piglets' survival and litter growth rates
}

\author{
Gianfranco Picone ${ }^{\dagger}$, Martina Zappaterra ${ }^{\dagger}$, Diana Luise ${ }^{\dagger}$, Alessia Trimigno, Francesco Capozzi, Vincenzo Motta,
} Roberta Davoli, Leonardo Nanni Costa, Paolo Bosi and Paolo Trevisi (i)

\begin{abstract}
Background: Colostrum is the first secretion produced by mammary glands during the hours immediately preceding and succeeding parturition. This secretion differs from milk and represents an essential vehicle of passive immunity, prebiotic compounds and growth factors involved in intestinal development. Most of the literature concerning colostrum composition refers mainly to human and cow; and little is known about pig colostrum metabolome and how it varies between pig breeds and different farrowing parity. Thus, the aim of the present research is to provide new information about pig colostrum composition and the associations between metabolites, the sows' breed and the survival and growth rates of their litters.
\end{abstract}

Results: Colostrum samples were gathered from 58 parturitions of sows belonging to three different breeds chosen for their importance in Italian heavy pig production: 31 Large White, 15 Landrace and 12 Duroc respectively. The defatted and ultrafiltered colostrum samples were analysed using ${ }^{1} \mathrm{H}-\mathrm{NMR}$ spectroscopy. Principal Components Analysis (PCA) was assessed on the obtained spectra. In addition, using a Stepwise Regression and a Linear Regression analyses the metabolites named after the signals assignment were tested for their associations with piglets' performances. Twenty-five metabolites were identified, comprehending monosaccharides, disaccharides (such as lactose), organic acids (lactate, citrate, acetate and formate), nitrogenous organic acids (such as creatine) and other compounds, including nucleotides. PCA results evidence a clustering due to breed and season effects. Lactose was the main compound determining the assignment of the samples into different clusters according to the sow breed. Furthermore, some metabolites showed to be associated with piglets' performance and survival traits: acetate and taurine were positively related to litter weight gain and piglets' survival rate, respectively, while dimethylamine and cis-aconitate were linked to new-borns' impaired ability to survive.

Conclusions: The results obtained suggest that colostrum composition is affected by breed, which, together with environmental conditions, may cause changes in colostrum metabolites content with possible consequences on piglets' performances. Among the identified metabolites, acetate, taurine, dimethylamine and cis-aconitate showed consistent associations with piglets' survival rate and litter weight gain, implying that these compounds may affect new-borns' ability to survive.

Keywords: Colostrum, ${ }^{1} \mathrm{H}-\mathrm{NMR}$ spectroscopy, Metabolome, Pig breeds, Piglets survival

\footnotetext{
* Correspondence: paolo.trevisi@unibo.it

${ }^{\dagger}$ Equal contributors

Department of Agricultural and Food Sciences (DISTAL), Alma Mater

Studiorum - University of Bologna, Viale Fanin 46, 40127 Bologna, Italy
} 


\section{Background}

The pre-weaning litter environment has been proven to affect pigs' development and performances during later life [1] and in particular colostrum intake, coupled with birth weight, was found to influence piglets' growth and mortality [2-4]. Colostrum provides new-borns with energy and passive immunity [5, 6]: in particular, most of the literature concerns the effects of the different immunoglobulins on piglets' health and survival capacities [7-9]. Studies on human and bovine colostrum suggested important roles in new-borns' health also for other bioactive molecules, such as nucleotides, oligosaccharides, organic acids and peptides [10-12], but little is known about the presence of these metabolites in sows' colostrum and their association with piglets' performances. Furthermore, to date little or no information about pig breed influence on colostrum composition is available and most of the knowledge about metabolites composition of swine colostrum was produced on samples gathered after farrowing induction, that may alter colostrum composition [13]. In this study, 58 colostrum samples were collected during a natural parturition with the aims i) to analyse through a ${ }^{1} \mathrm{H}-\mathrm{NMR}$-based metabolomics approach the colostrum compounds with a maximum $10 \mathrm{kDa}$ molecular weight in three pig breeds, ii) to evaluate breed and season effects on the colostrum composition, iii) to test the associations between the identified metabolites, the sow reproductive performance, and the piglets' survival and growth rates at day three after birth.

\section{Methods}

\section{Animals and sampling}

Colostrum samples were collected from 58 farrowings of pure breed sows: 12 from Duroc (D), 15 from Landrace (L) and 31 from Large White (LW) sows. The number of samples collected per breed reflected the different numbers of individuals reared in Italy for these three pig breeds. All sows were raised in the same commercial farm from May 2014 to August 2015, under the same indoor environmental conditions with an automated system to control temperature and relative humidity. Following the EU rules to guarantee pig welfare, from the fourth week post insemination, the sows were kept in groups of 10 and fed twice a day with $2.5 \mathrm{~kg}$ of the same flour mash diet (Table 1). Five days before the farrowing, the sows were moved into the farrowing room and housed in single cages, fed twice a day until farrowing with the same diet. Sows had free access to water along all the experimental period. For this trial, we have considered exclusively sows that were not treated with antibiotics and medical products during gestation and lactation periods.
Table 1 Ingredients and calculated composition of the sows' diet expressed on a dry matter basis

\begin{tabular}{|c|c|c|}
\hline & Units & Dry matter \\
\hline \multirow[t]{2}{*}{ Digestible energy } & kcal/ration & $3,320.76$ \\
\hline & $\mathrm{kcal} / \mathrm{d}$ & $6,641.52$ \\
\hline \multicolumn{3}{|l|}{ Ingredients } \\
\hline Barley & $\%$ & 42.00 \\
\hline Wheat bran & $\%$ & 30.00 \\
\hline Wheat flour & $\%$ & 11.00 \\
\hline Soya & $\%$ & 7.00 \\
\hline Corn & $\%$ & 4.30 \\
\hline Whole soybean & $\%$ & 2.00 \\
\hline Calcium carbonate & $\%$ & 1.63 \\
\hline Bicalcium phosphate & $\%$ & 0.65 \\
\hline Fish oil & $\%$ & 0.50 \\
\hline Sodium chloride & $\%$ & 0.40 \\
\hline Mycotoxin binder & $\%$ & 0.20 \\
\hline L-lysine monohydrochloride & $\%$ & 0.15 \\
\hline Choline & $\%$ & 0.11 \\
\hline Magnesium sulphate anhydrous & $\%$ & 0.05 \\
\hline Threonine & $\%$ & 0.05 \\
\hline Methionine & $\%$ & 0.04 \\
\hline \multicolumn{3}{|l|}{ Composition } \\
\hline Crude protein & $\%$ & 16.48 \\
\hline Crude fat & $\%$ & 3.70 \\
\hline Crude fiber & $\%$ & 7.27 \\
\hline Starch & $\%$ & 37.57 \\
\hline Starch + Sugar & $\%$ & 41.03 \\
\hline Calcium & g & 8.00 \\
\hline Available phosphorus & g & 8.60 \\
\hline Digestible phosphorus & g & 4.51 \\
\hline Available lysine & g & 8.59 \\
\hline Digestible lysine & g & 7.23 \\
\hline Available methionine & g & 2.87 \\
\hline Digestible methionine & g & 2.51 \\
\hline Methionine + Cysteine & g & 5.99 \\
\hline Digestible methionine + Cysteine & g & 5.06 \\
\hline Threonine & $\mathrm{g}$ & 6.14 \\
\hline Tryptophan & $g$ & 2.03 \\
\hline
\end{tabular}

Farrowing was not induced, and the colostrum sampling was carried out during natural parturition, after the birth of the first piglet and before the parturition of the last, across all teats. Furthermore, the sows that showed long parturitions or required farrowing induction were excluded from the sampling, in order to avoid possible confounds of colostrum variations. All samples were immediately frozen at $-20{ }^{\circ} \mathrm{C}$ and 
then stored at $-80{ }^{\circ} \mathrm{C}$ until the samples preparation for ${ }^{1} \mathrm{H}-\mathrm{NMR}$ analysis.

The parity, the date and the season of the farrowing and the reproductive performance data were recorded for each sow. The number of alive piglets and the litter body weight (LBW) were recorded at birth and at d 3, cleansed of the weight of the dead piglets. The litter weight gain (LWG) was then calculated for the period from birth to $d 3$. Furthermore, the number of weaners per litter was recorded as well as the occurrence of diarrhea during suckling $(1=$ presence of diarrhea events from piglets' birth until weaning, $0=$ absence of diarrhea event).

\section{Colostrum preparation for ${ }^{1} \mathrm{H}-\mathrm{NMR}$ analysis}

Colostrum was thawed, carefully mixed by inversion, and $15 \mathrm{~mL}$ of each colostrum sample was diluted 1:1 with pure water. To each diluted sample, $0.02 \%$ of sodium azide was added, to inhibit bacterial growth during the sample preparation. Then the sample was defatted through a centrifugation at $4{ }^{\circ} \mathrm{C}$ for $30 \mathrm{~min}$ at $1,500 \times g$. The aqueous phase was transferred to a clean Falcon tube avoiding the outer layer of fat, and centrifuged again; this procedure was repeated three times. $5 \mathrm{~mL}$ of the obtained aqueous phase was then transferred in Amicon Ultra $10 \mathrm{kDa}$ membrane centrifugal filters (Merck Millipore, Merck KGaA, Darmstadt, Germany) and filtered by centrifugation at room temperature for $90 \mathrm{~min}$ at 5,500 $\times \mathrm{g}$. This step was needed to eliminate immunoglobulins and other proteins with high molecular weight. The eluted sample was then weighted and lyophilized and stored in a dry environment at room temperature until analyses.

\section{${ }^{1} \mathrm{H}-\mathrm{NMR}$ measurements}

At the time of sample processing, for each milligram of the lyophilized sample, $250 \mu \mathrm{L}$ distilled water was added. Eighty $\mu \mathrm{L}$ of the regenerated sample were centrifuged at $14,000 \times g$ for 5 min (Scilogex D3024 High Speed MicroCentrifuge, Rocky Hill, CT, USA) and then added to $720 \mu \mathrm{L}$ of distilled water and $100 \mu \mathrm{L}$ of a $\mathrm{D}_{2} \mathrm{O}$ solution of 3-(trimethylsilyl)-propioniate-2,2,3,3- $\mathrm{d}_{4}$ (TMSP) (Cambridge Isotope Laboratories Inc., Tewksbury, MA, USA) with a final concentration of $6.25 \mathrm{mmol} / \mathrm{L}$. ${ }^{1} \mathrm{H}-\mathrm{NMR}$ spectra were recorded at $298 \mathrm{~K}$ with an AVANCE spectrometer (Bruker BioSpin, Karlsruhe, Germany) operating at a frequency of $600.13 \mathrm{MHz}$, equipped with an autosampler with 60 holders. The HOD residual signal was suppressed by applying the NOESYGPPR1D sequence (a standard pulse sequence included in the Bruker library) incorporating the first increment of the NOESY pulse sequence and a spoil gradient. Each spectrum was acquired using $32 \mathrm{~K}$ data points over a 7,211.54 $\mathrm{Hz}$ spectral width (12 ppm) and adding 256 transients. A recycle delay of
$5 \mathrm{~s}$ and a $90^{\circ}$ pulse of $11.4 \mu \mathrm{s}$ were set up. Acquisition time $(2.27 \mathrm{~s})$ and recycle delay was adjusted to be 5 times longer than the longitudinal relaxation time of the protons under investigation, which has been no longer than $1.4 \mathrm{~s}$. The data were Fourier transformed and phase and baseline corrections were automatically performed using TopSpin software, version 3.0 (Bruker BioSpin, Karlsruhe, Germany). Signals were assigned through a combination of literature assignments and by the use of a multimedia library included in Chenomx NMR Suite 8.2 professional software (Chenomx, Edmonton, Alberta, Canada).

\section{Data analysis}

Sows were grouped according to the parity order: from 1 to 3 (PO1; 27 sows) and parities equal to or higher than 4 (PO2; 31 sows). The parturition season was also taken into account and was assigned as follows: $1=$ parturition between the $1^{\text {st }}$ of December and the $28^{\text {th }}$ of February; 2 = between the $1^{\text {st }}$ of March and the $31^{\text {st }}$ of May; $3=$ between the $1^{\text {st }}$ of June and the $31^{\text {st }}$ of August; 4 = between the $1^{\text {st }}$ of September and the $30^{\text {th }}$ of November the average temperature per seasons registered was respectively $5.6{ }^{\circ} \mathrm{C} \pm 0.9{ }^{\circ} \mathrm{C}$ for season $1,16.5^{\circ} \mathrm{C} \pm 4.3^{\circ} \mathrm{C}$ for season 2 , $25.2{ }^{\circ} \mathrm{C} \pm 4.3{ }^{\circ} \mathrm{C}$ for season 3 and $16.2{ }^{\circ} \mathrm{C} \pm 4.2{ }^{\circ} \mathrm{C}$ for season 4 . Among the studied animals, 6 sows gave birth during season 1, 19 during season 2, 21 during season 3 and 12 during season 4 . The data collected about piglets' performances were analysed using an analysis of variance (ANOVA) with the aim to identify possible differences linked to sows' breed.

Statistical analyses on spectra data were performed using $\mathrm{R}$ computational language (ver. 3.1.2) [14] and MATLAB (ver R2014b, MathWorks Inc.). Each ${ }^{1} \mathrm{H}-$ NMR spectrum was processed by means of scripts developed in-house as follows: spectrum baseline was adjusted by employing the signals identification algorithm named "baseline.peakDetection" from $\mathrm{R}$ (version 3.1.2) package "Baseline" (https://cran.r-project.org/web/ packages/baseline/index.html).

Chemical shift referencing was performed by setting the TMSP signal to $0.00 \mathrm{ppm}$. The following spectral regions were removed prior to data analysis: the regions including only noise (the spectrum edges between 11.00 and $8.65 \mathrm{ppm}$ and between 0.15 and $-1.00 \mathrm{ppm}$ ), the ${ }^{1} \mathrm{H}-\mathrm{NMR}$ signal which is strongly affected by the residual solvent signals (water, between 4.90 and $4.50 \mathrm{ppm}$ ) and the glycerol's signals from 3.82 and $3.76 \mathrm{ppm}$, from 3.69 and $3.63 \mathrm{ppm}$ and from 3.60 and $3.54 \mathrm{ppm}$. Spectra were then normalized by means of probabilistic quotient normalization method (PQN) [15] and binned. The first normalization operation is aimed at removing possible dilution effects. The second one avoids the effect of signals misalignments among different 
spectra due to variations in chemical shift of signals belonging to some titratable acids. The binning operation is performed by subdividing the spectra into 369 bins, each integrating 120 data points ( $0.0219 \mathrm{ppm}$ each). In order to focus on the real information contained in the spectra, bins that had an average higher value than noise were selected. In this way, a total of 201 bins were kept.

The spectra obtained were then analysed through an unsupervised multivariate approach using PCA. The PCA was conducted on the 201 bins matrix to identify the outlier samples and test the existence variables contributing to samples clustering. The multivariate models were calculated and the results were visualized on both scores and loadings' plot. In order to determine the spectral regions encompassing most of the discriminative information, bins with a loading value greater than $1 \%$ of the overall standard deviation of all loading values were selected. The identified metabolites were grouped in a new dataset named $\mathrm{C}$-dataset. The $\mathrm{C}$-dataset was used to conduct an ANOVA with the aim to confirm if the amounts of the identified compounds were influenced by the effects of breed and farrowing season identified with the PCA and parity order. The model utilized for this analysis was:

$$
y=\beta 0+\beta \mathrm{p}^{\times} b+\beta \mathrm{p}^{\times} s+\beta \mathrm{p}^{\times} o+\beta \mathrm{p}^{\times} n+\beta \mathrm{p}^{\times}\left(b^{\times} s\right)+E
$$

Where:

$\beta 0$ was the intercept;

$\beta p$ was the corresponding regression coefficient;

$y$ was the amount of each identified metabolite;

$b$ was the sow breed (LW; D; LA);

$s$ was the farrowing season $(1 ; 2 ; 3 ; 4)$;

$o$ was the parity order (PO1; PO2);

$n$ was the number of piglets born alive per litter;

$b \times s$ was the interaction between breed and season;

$E$ was the error.

This first part was conducted to test if sows' breed influences colostrum profile and if in addition to breed there are other "environmental" variables affecting colostrum quality (such as the farrowing season, the parity order or the litter size).

Then, a Stepwise Regression analysis was used to select, among the metabolites included in the $\mathrm{C}$-dataset and sows' reproductive performances, the variables that influenced the LWG, the number of dead piglets from birth until d 3 or the number of piglets dead from day 3 to weaning. This statistical analysis involves starting with no variables in the model and adding gradually each metabolite and sow reproductive parameter (the litter weight and the number of alive piglets at birth) to evaluate which one of the colostrum identified compounds and sows' reproductive abilities most influenced the piglets' survival and growth. The results obtained from the
Stepwise Regression analysis were then confirmed through Generalized Linear Model (GLM). The GLM model for LWG included the sows' breed, the average piglet's weight at birth and the interaction between sows' breed and acetate as fixed effects. The GLM model for the number of dead piglets from birth until day three included the sows' breed, the number of alive piglets at birth, the interaction between sows' breed and dimethylamine and the interaction between sows' breed and taurine as fixed effects. For the number of weaned piglets the GLM model included as fixed factors the sows breed, the number of alive piglets at birth, the interaction between sows' breed and cis-aconitate.

Finally, all the variables that did not show an effect on the dependent variables were removed from the model and only the significant effects were maintained.

The prcomp function of $\mathrm{R}$ environment was used to perform the PCA analysis on bins matrix [16]. The ANOVA analysis, the Stepwise Regression analysis, and the regression model were carried out on SAS software using PROC REG and PROC GLM respectively (SAS ${ }^{\circ}$ 9.4, SAS Inst. Inc., Cary, NC). Results were considered significant at $P \leq 0.05$ and tendencies at $0.05 \leq P \leq 0.10$.

\section{Results}

\section{Dataset description}

Table 2 detailed the data about sows, litters and piglets included in the study. D sows had on average a lower number of piglets born alive per litter $(8.92 \pm 2.28)$ with respect to $\mathrm{L}(12.60 \pm 1.72)$ and LW $(11.90 \pm 2.26)(P<$ $0.0001)$, while the new-borns of $\mathrm{L}$ and $\mathrm{LW}$ breeds presented a lower weight at birth $(1.38 \pm 0.15 \mathrm{~kg}$ and $1.43 \pm$ $0.16 \mathrm{~kg}$, respectively) compared to D piglets (on average $1.59 \pm 0.23 \mathrm{~kg})(P=0.007)$.

\section{Colostrum spectra}

Figure 1 shows a ${ }^{1} \mathrm{H}-\mathrm{NMR}$ profile of defatted and ultrafiltered sow colostrum. The ${ }^{1} \mathrm{H}$ spectrum is mainly dominated by the carbohydrate signals overlapping in the midfield region between 3.49 and $4.49 \mathrm{ppm}$ (Fig. 1b). Those belong to lactose and nucleotides sugars such as UDP-glucose and UDP-galactose and nucleotide as UMP. Amino acids mainly fall in the upfield region, between 0.99 and $3.49 \mathrm{ppm}$, together with the signals of organic acids (Fig. 1a) and creatine (3.04-3.05 ppm). In this part of the spectrum fall also signals from threonine and lactic acid (both at $1.33 \mathrm{ppm})$, alanine (1.49 ppm), acetic acid (1.92 ppm), succinic acid (2.41 ppm) and citric acid (2.54 and $2.67 \mathrm{ppm})$. Finally, in the downfield region (Fig. 1c) signals of different phenolic compounds can be observed, but in this case, only formic acid was assigned (8.4 ppm), together with signals from the nucleotide sugars UDP-glucose and UDP-galactose (5.56 ppm, 7.9-8 ppm) and UMP (8.1 ppm, 5.98-5.99 ppm, 
Table 2 Phenotypic differences observed for the parameters measured in Duroc, Landrace and Large White litters

\begin{tabular}{|c|c|c|c|c|c|c|}
\hline Variables & $D^{a}$ & $L^{b}$ & $\mathrm{LW}^{\mathrm{c}}$ & Total & $F$ value & $P$-value \\
\hline Number of sows & 12 & 15 & 31 & 58 & & \\
\hline Order of parturition & 2.750 & 4.067 & 4.161 & 3.845 & 3.555 & 0.035 \\
\hline \multicolumn{7}{|c|}{ Number of piglets born alive per litter } \\
\hline Mean & 8.917 & 12.600 & 11.903 & 11.466 & 11.85 & $<.0001$ \\
\hline SD & 2.275 & 1.724 & 2.256 & 2.494 & & \\
\hline \multicolumn{7}{|c|}{ Average LBW at birth ${ }^{d}, \mathrm{~kg}$} \\
\hline Mean & 14.033 & 17.207 & 16.890 & 16.381 & 5.503 & 0.006 \\
\hline SD & 3.679 & 2.081 & 2.828 & 3.060 & & \\
\hline \multicolumn{7}{|c|}{ Average piglet's weight at birth, kg } \\
\hline Mean & 1.588 & 1.376 & 1.432 & 1.450 & 5.437 & 0.007 \\
\hline SD & 0.226 & 0.153 & 0.155 & 0.184 & & \\
\hline
\end{tabular}

Number of alive piglets per litter at $\mathrm{d} 3$

$\begin{array}{lllllll}\text { Mean } & 8.250 & 12.133 & 10.871 & 10.655 & 12.55 & <.0001 \\ \text { SD } & 1.865 & 1.767 & 2.291 & 2.453 & & \end{array}$

Number of dead piglets per litter at $d 3$

\begin{tabular}{|c|c|c|c|c|c|c|}
\hline Mean & 1.600 & 1.750 & 1.583 & 1.619 & 0.104 & 0.902 \\
\hline SD & 1.342 & 0.500 & 0.996 & 0.974 & & \\
\hline \multicolumn{7}{|c|}{ Average LBW at $\mathrm{d} 3^{\mathrm{d}}, \mathrm{kg}$} \\
\hline Mean & 16.400 & 21.167 & 19.758 & 19.428 & 4.948 & 0.010 \\
\hline SD & 3.993 & 3.059 & 4.264 & 4.211 & & \\
\hline \multicolumn{7}{|c|}{ Average piglet's weight at $\mathrm{d} 3, \mathrm{~kg}$} \\
\hline Mean & 2.001 & 1.761 & 1.826 & 1.846 & 4.326 & 0.018 \\
\hline SD & 0.275 & 0.240 & 0.213 & 0.244 & & \\
\hline \multicolumn{7}{|l|}{ LWG ${ }^{e}, \mathrm{~kg}$} \\
\hline Mean & 3.085 & 4.453 & 4.103 & 3.983 & 0.102 & 0.902 \\
\hline SD & 0.864 & 1.461 & 1.771 & 1.598 & & \\
\hline
\end{tabular}

Number of weaned piglets

$\begin{array}{lllllll}\text { Mean } & 7.333 & 11.133 & 10.032 & 9.759 & 11.59 & <.0001 \\ \text { SD } & 1.875 & 1.552 & 2.316 & 2.423 & & \end{array}$

Incidence of diarrhoea

$\begin{array}{llllllll}\text { Mean } & 3 & 1 & 4 & 8 & 1.048 & 0.357\end{array}$

${ }^{\mathrm{a}}$ Duroc

${ }^{\mathrm{b}}$ Landrace

'Large White

ditter body weight

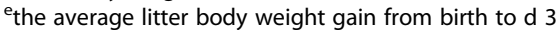

$4.42 \mathrm{ppm}$ ) as listed in Table 3. The 25 compounds have been identified through a combination of literature assignments [17] and by the use of a multimedia library included in Chenomx NMR Suite 8.2 professional software (Chenomx, Edmonton, Alberta, Canada).

\section{Factors affecting colostrum composition}

After alignment, normalization and binning, the dataset contained 58 colostrum spectra characterized by 201 bins and PCA was applied on it to investigate differences on the metabolome between groups. In the total colostrum spectra, no PCA clustering for sow's parity order was identified (data not shown). Figure $2 \mathrm{a}$ and $\mathrm{b}$ show that samples clustered on PC1-PC2 due to the effect of the sow breeds (Fig. 2a) and on PC2-PC3 due to the farrowing seasons (Fig. 2b). The PC1 explained the $81 \%$ of the total variance and separated the colostrum spectra of D and LW, while PC2 (10\% of the variance) discriminated the $\mathrm{L}$ colostrum composition into two clusters. The PC2 together with the PC3 explained the $14 \%$ of the total variance. This plot highlights the season effect, in particular along PC2 where differences in the colostrum spectra due to seasons 1 and 4 (winter-autumn) against season 2 and 3 (spring-summer) are visible. The weighting of each variable (bin) is represented by the loadings plot in Fig. $2 \mathrm{c}$ and $\mathrm{d}$ in which are displayed the loadings from PC1 and PC2 respectively as a bar plot, where each bar corresponds to a single spectral variable (bin). The main bins accounting for the spectral differentiation and their relative chemical shift were listed in the Additional file 1: Table S1 (SS1). As emerging from the SS1 table, most of the signals included in these discriminant bins were assigned to the corresponding metabolites. The C-dataset, which was used for the following statistical analyses, resulted as being composed of 25 metabolites, listed in Table 3 .

The parity, breed and season effects on colostrum composition were then confirmed through the ANOVA analysis on the identified metabolites described in the Cdataset, and the results are reported in Table 4. Sows' parity order and the interaction between sows' breed and season did not show significant associations with the metabolites amount, while the number of piglets born alive showed few significant associations $(P<0.05$ only for $\mathrm{N}$-acetilglucosamine and UDP-glucose - data not shown). Table 4 , reports the $P$ values for breed and season, which showed the strongest effects on ultrafiltered colostrum metabolome. Indeed, the amounts of lactose, UDP-glucose, glycolate and UDP-galactose were strongly associated to breed $(P<0.001)$, citrate and $\mathrm{N}$-acetilglucosamine showed breed-related differences $(P<0.01)$, as well as alanine, succinate, creatine, creatine phosphate, cis-aconitate, O-acetylcholine, sn-glycerophosphocholine, UDP-N-acetilglucosamine, taurine and myo-inositol $(P<0.05)$. In particular, the colostrum of L samples showed upper signals for UDPglucose, UDP-galactose and sn-glycerophosphocholine compared to the other two breeds, while LW colostrum was characterized by a greater quantity of lactose, taurine, myo-inositol and glycolate than L and D colostrum. Season as well explained a significant part of the variations observed for acetate, dimethylamine, creatine phosphate, creatinine, cis-aconitate, glycolate and formate $(P<0.001)$, 


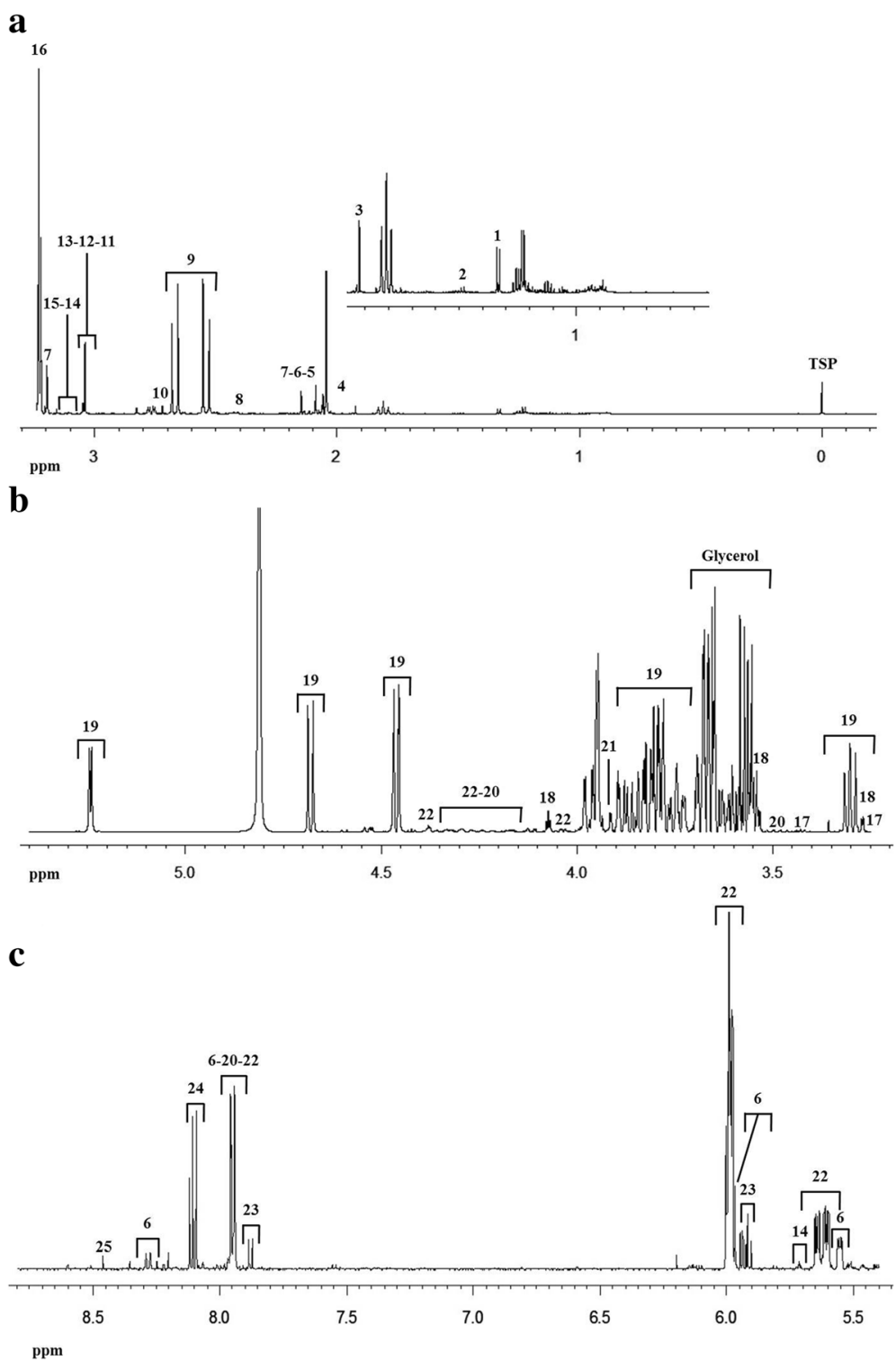

Fig. 1 Typical ${ }^{1} \mathrm{H}-\mathrm{NMR}$ spectrum of aqueous extract of colostrum. The spectrum has been split into three parts for the sake of clarity. Some resonances have been assigned by using Chenomx software and listed in Table 3: a Aliphatic or upfield region; b Carbohydrate or midfield region, characterized by the presence of signals belonging to sugars and glycerol and c Aromatic region or downfield region

for creatine, taurine, UDP-galactose and UMP $(P<0.01)$ and for alanine $(P<0.05)$.

\section{Factors affecting litter performances}

The Stepwise Regression analysis revealed that, in addition to the influence of sows' reproductive performances (the litter weight and the number of alive piglets at birth), some specific metabolites can be associated to piglets' survival and growth parameters (Table 5). In particular, the litter weight at birth and the concentration of acetate significantly entered in the model for LWG $(P<0.0001$ and $P=0.002$, respectively); the higher number of alive piglets at birth and the increased concentration of colostrum cisaconitate were associated with the number of weaned piglets $(P<0.0001$ and $P=0.019$, respectively), while dimethylamine $(P=0.0002)$ and taurine $(P=0.013)$ entered as variables in the model for the number of dead piglets per litter at $\mathrm{d} 3$. There was no influence of farrowing season and parity order on LWG, the number of weaned pigs or the number of dead piglets at $\mathrm{d} 3$.

The outcomes of the Stepwise Regression analysis were then tested with the GLM, and the results reported in Table 6. Both the higher average piglets' weight at birth $(P<0.0001)$ and the interaction between 
Table 3 Assignment table of the identified metabolites present in the ${ }^{1} \mathrm{H}-\mathrm{NMR}$ spectra of colostrum

\begin{tabular}{|c|c|c|}
\hline $\begin{array}{l}\text { Assigned } \\
\text { number }\end{array}$ & ${ }^{1} \mathrm{H}$ chemical shift, $\mathrm{ppm}^{\mathrm{a}}$ & Compound \\
\hline 1 & $1.332(d)$ & Lactate \\
\hline 2 & $1.486(d)$ & Alanine \\
\hline 3 & $1.923(\mathrm{~s})$ & Acetate \\
\hline 4 & $2.028(s)$ & N-Acetylglutamate \\
\hline 5 & $2.063(\mathrm{~s})$ & N-Acetylglucosamine \\
\hline 6 & $\begin{array}{l}2.089(\mathrm{~s})-5.552(\mathrm{dd})-5.967(\mathrm{~d})- \\
7.944 \text { (d) - } 8.287(\mathrm{~d})\end{array}$ & UDP-N-Acetylglucosamine \\
\hline 7 & $2.147(\mathrm{~s})-3.222(\mathrm{~s})$ & O-Acetylcholine \\
\hline 8 & $2.408(s)$ & Succinate \\
\hline 9 & $2.539(d)-2.667(d)$ & Citrate \\
\hline 10 & $2.720(s)$ & Dimethylamine \\
\hline 11 & $3.039(\mathrm{~s})$ & Creatine \\
\hline 12 & $3.046(s)$ & Creatine phosphate \\
\hline 13 & $3.050(\mathrm{~s})$ & Creatinine \\
\hline 14 & $3.119(d)-5.712(m)$ & cis-Aconitate \\
\hline 15 & $3.204(\mathrm{~s})$ & Choline \\
\hline 16 & $3.231(\mathrm{~s})-4.330(\mathrm{~m})$ & sn-Glycerophosphocholine \\
\hline 17 & $3.272(t)-3.532(d d)-4.073(t)$ & Myo-Inositol \\
\hline 18 & $3.259(\mathrm{t})-3.428(\mathrm{t})$ & Taurine \\
\hline 19 & $\begin{array}{l}3.302(\mathrm{t})-3.684: 3.906(\mathrm{~m}), 3.980(\mathrm{~d}) \\
4.461(\mathrm{~d})-4.679(\mathrm{~d})-5.243(\mathrm{~d})\end{array}$ & Lactose \\
\hline 20 & $\begin{array}{l}3.480(\mathrm{~s})-4.142: 4.278(\mathrm{~m})-5.607 \\
(\mathrm{dd})-5.967(\mathrm{~m})-7.940(\mathrm{~d})\end{array}$ & UDP-glucose \\
\hline 21 & 3.935 (s) & Glycolate \\
\hline 22 & $\begin{array}{l}\text { 4.142:4.278 (m) - } 4.379(m)-5.664 \\
\text { (dd)- } 5.990(m)-7.942-7.995(d)\end{array}$ & UDP-galactose \\
\hline 23 & $5.917(d)-7.879(d)$ & Uridine \\
\hline 24 & $8.406(s)$ & Formate \\
\hline 25 & $4.423(t)-5.990(m)-8.102(d)$ & UMP \\
\hline
\end{tabular}

The assignments were obtained at $\mathrm{pH} 7.420$. Chemical shift values are referenced to TMSP proton signals at $0.00 \mathrm{ppm}$. Glycerol $(3.568,3.661$ and $3.793 \mathrm{ppm}$ has not been listed as it has not been included in the PCA)

${ }^{a} d$, doublet; dd, doublet of doublets; $m$, multiplet; s, singlet; $t$, triplet

breed and colostrum acetate concentration $(P=0.013)$ positively affected the LWG (Table 6). The number of alive piglets at birth $(P=0.004)$ and the interaction between cis-aconitate colostrum content and breed $(P=0.008)$ were significantly associated with the number of weaned piglets, while the effect of breed alone presented a trend towards significance $(P=0.061)$. In addition, the number of dead piglets at d 3 was related to breed $(P=0.026)$, to the interaction between the concentration of dimethylamine and breed $(P=0.001)$, to the interaction between taurine concentration and breed $(P=0.036)$ and to the number of alive piglets at birth $(P=0.031)$.

\section{Discussion}

This is the first study describing in three pig breeds the defatted colostrum metabolome profile $<10 \mathrm{kDa}$, the factors underlying its composition and the associations between colostrum metabolites and litter's growth and survival parameters during suckling.

The three breeds showed different reproductive abilities in accordance with the literature $[17,18]$, with L and LW sows exhibiting a higher average number of piglets alive at birth compared to D sows. These differences between breeds are also visible at the colostrum composition level $[19,20]$ : considering the whole spectrum, the colostrum composition of $\mathrm{L}$ sows showed to be mainly affected by season (explained by PC2), while LW and D breeds displayed clustering tendency for PC1, with the colostrum lactose amount explaining most of the colostrum composition differences between breeds according to [20]. In particular, LW breed samples presented higher values of lactose according to [20]. Lactose concentration in cow milk is commonly associated with the health status of the mammary gland, as higher lactose concentrations are positively correlated to healthier mammary glands and low amounts of this sugar indicate the existence of intramammary infections [21]. Considering the data provided by the present work, it is not possible to support the same association in lactating sows, due to the absence of reference value for sow milk and colostrum.

Furthermore, the obtained colostrum spectra were affected also by the farrowing season: the samples gathered during winter and autumn exhibited differences in colostrum compositions with respect to colostrum secreted during spring and summer. These differences could be ascribed to the environmental conditions affecting sows' performances. Indeed, even if the sows were reared in temperature-controlled and humiditycontrolled environment, heat stress may occur in hotter months and is an important factor that must be taken into account when dealing with results obtained in the Mediterranean areas. Compounds such as acetate, which showed to be more abundant during cold seasons, may reflect the different energy requirements of sows during cold months. Acetate is of particular interest for milk composition as it is a precursor of the fat synthesized in mammary glands [22] and it could be the product of fermentations taking place in sows' hindgut.

In addition, farrowing season affected also the creatine pathway: in particular, creatine and creatine-phosphate amounts during the period ranging from September to February were significantly lower than in spring and summer; on the contrary, creatinine was higher during the same period. Creatine is an important nutrient for the new-born, as it functions as high-energy phosphate buffer and it is essential in tissues with a high energy 

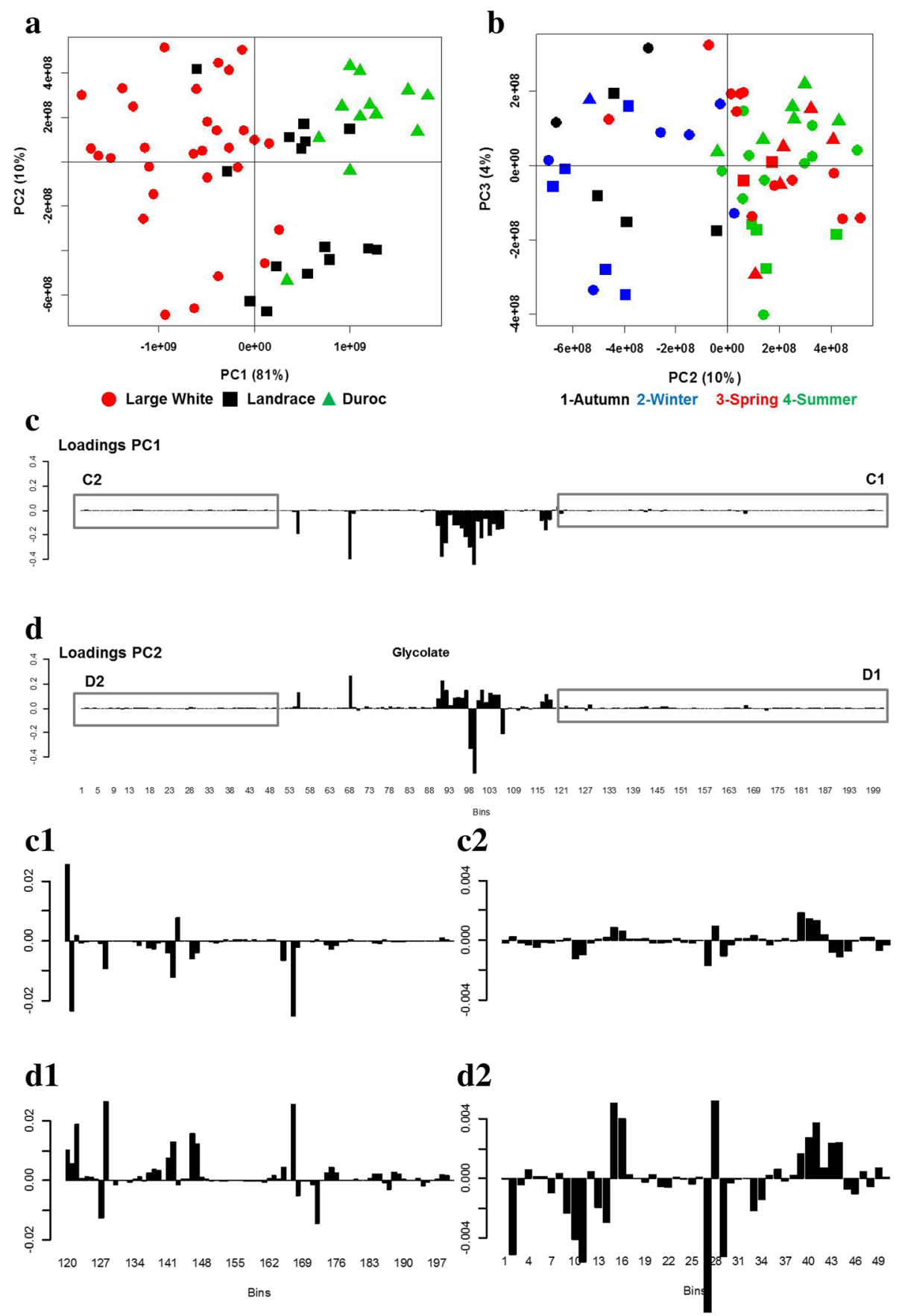

Fig. 2 Score plots of PCA on ${ }^{1} \mathrm{H}-\mathrm{NMR}$ binned spectra of colostrum. a PC1 vs. PC2 and $\mathbf{b} P C 2$ vs. PC3. The first two PCs represent the $91 \%$ of the total variance. $\mathbf{c}-\mathbf{d}$ Loadings bar-plot for spectral bins along PC1 and PC2 respectively. Downfield (C1 and D1) and upfield (C2 and D2) regions of C and $\mathrm{D}$ loadings bar-plot were expanded on the vertical scale to appreciate the presence of small bar plot

demand such as muscle and brain [23]. In mice, it has been shown that milk creatine is extracted from the circulating plasma by the mammary gland, which conversely has little or no capacity to synthesize creatine [24]. No research data are available for sow colostrum, but it can be assumed that also in this case variations in colostrum may reflect variations in blood creatine concentration. Here the variations in the ratio creatine and creatine-phosphate to creatinine may have resulted from a higher degradation of the first two compounds into creatinine during the hotter season. The increasing amount of creatinine level is in general associated with a higher mobilization of stored proteins and indirectly with fat and lean levels in the body mass [25]. A recent 
Table 4 Effects of sow breed and season on the identified colostrum metabolites

\begin{tabular}{|c|c|c|c|c|c|c|c|c|c|c|c|}
\hline \multirow[t]{2}{*}{ Metabolite } & \multicolumn{3}{|c|}{ Breed $^{\mathrm{a}}$} & \multirow[t]{2}{*}{ SEM } & \multirow{2}{*}{$\begin{array}{l}P \text { - } \\
\text { value }\end{array}$} & \multicolumn{4}{|c|}{ Season $^{b}$} & \multirow[t]{2}{*}{ SEM } & \multirow{2}{*}{$\begin{array}{l}P \text { - } \\
\text { value }\end{array}$} \\
\hline & $\mathrm{D}$ & L & LW & & & 1 & 2 & 3 & 4 & & \\
\hline Lactate & 5.38 & 6.7 & 8.88 & 1.85 & 0.506 & 4.93 & 10.18 & 8.71 & 4.13 & 1.81 & 0.495 \\
\hline Alanine & 1.77 & 2.2 & 2.44 & 0.17 & 0.04 & 1.65 & 2.5 & 2.51 & 1.88 & 0.17 & 0.04 \\
\hline Acetate & 9.57 & 11.17 & 9.9 & 0.91 & 0.378 & 13.59 & 7.55 & 5.95 & 13.77 & 0.89 & $<.0001$ \\
\hline N-Acetylglutamate & 6.35 & 9.9 & 14.03 & 3.77 & 0.453 & 7.94 & 9.69 & 8.53 & 14.21 & 3.69 & 0.776 \\
\hline N-Acetylglucosamine & 10.9 & 15.4 & 11.7 & 1.6 & 0.003 & 10.6 & 14 & 13.8 & 12.3 & 1.6 & 0.149 \\
\hline UDP-N-Acetylglucosamine & 22.4 & 34.4 & 33.9 & 2.2 & 0.014 & 26.2 & 33.4 & 33.8 & 27.4 & 2.1 & 0.324 \\
\hline O-Acetylcholine & 77.1 & 196.9 & 156.6 & 13.9 & 0.002 & 101.7 & 148.4 & 171.7 & 152.3 & 13.6 & 0.115 \\
\hline Succinate & 2.21 & 3.26 & 3.5 & 0.19 & 0.01 & 2.59 & 3.26 & 3.55 & 2.55 & 0.21 & 0.329 \\
\hline Citrate & 209 & 301 & 257 & 13 & 0.002 & 246 & 286 & 265 & 228 & 12 & 0.101 \\
\hline Dimethylamine & 2.86 & 4.44 & 4.51 & 0.49 & 0.091 & 2.3 & 5.19 & 5.39 & 2.85 & 0.48 & 0.0003 \\
\hline Creatine & 39.8 & 59.9 & 58.7 & 3.4 & 0.014 & 40.9 & 59 & 64.7 & 46.6 & 3.3 & 0.002 \\
\hline Creatine Phosphate & 3.4 & 7.99 & 8.01 & 0.88 & 0.015 & 1.9 & 8.5 & 10.78 & 4.69 & 0.86 & $<.0001$ \\
\hline Creatinine & 13.6 & 16.7 & 16.5 & 1.1 & 0.622 & 19.9 & 11.8 & 11.6 & 19.2 & 1.1 & $<.0001$ \\
\hline cis-Aconitate & 1.41 & 1.93 & 1.74 & 0.14 & 0.029 & 1.1 & 2.14 & 2.28 & 1.26 & 0.14 & $<.0001$ \\
\hline Choline & 7.82 & 10.62 & 9.91 & 1.19 & 0.665 & 8.86 & 11.64 & 9.43 & 7.87 & 1.16 & 0.961 \\
\hline sn-Glycerophosphocholine & 446 & 543 & 414 & 38 & 0.038 & 430 & 457 & 507 & 477 & 37 & 0.507 \\
\hline Myo-inositol & 63.53 & 76.95 & 82.86 & 3.76 & 0.012 & 62.58 & 73.17 & 81.13 & 80.91 & 3.68 & 0.085 \\
\hline Taurine & 1.57 & 4.1 & 6.05 & 0.87 & 0.015 & 0.98 & 6.23 & 6.19 & 2.21 & 0.85 & 0.005 \\
\hline Lactose & 458 & 579 & 811 & 30 & $<.0001$ & 535 & 644 & 667 & 619 & 30 & 0.136 \\
\hline UDP-glucose & 6.07 & 9.78 & 6.23 & 0.54 & $<.0001$ & 6.08 & 7.3 & 8.09 & 7.97 & 0.54 & 0.198 \\
\hline Glycolate & 28.1 & 39.8 & 45.8 & 2.4 & 0.0006 & 28.4 & 41.8 & 45.9 & 35.6 & 2.3 & 0.001 \\
\hline UDP-galactose & 32.6 & 74 & 42.5 & 4 & $<.0001$ & 39.3 & 54.2 & 61.4 & 44 & 3.9 & 0.005 \\
\hline Uridine & 3.14 & 3.72 & 3.23 & 0.38 & 0.601 & 3.05 & 3.55 & 3.49 & 3.37 & 0.38 & 0.463 \\
\hline Formate & 4.49 & 4.43 & 4.03 & 0.35 & 0.06 & 6.27 & 3.04 & 2.29 & 5.67 & 0.34 & $<.0001$ \\
\hline UMP & 13.3 & 24.2 & 21.6 & 1.7 & 0.096 & 21.82 & 16.04 & 16.84 & 24.08 & 1.91 & 0.01 \\
\hline
\end{tabular}

Mean of the identified metabolites are expressed as absolute area

${ }^{a}$ The Breed is assigned as D for Duroc, L for Landrace and LW for Large White

bThe seasons were assigned as follows: 1 = if the parturition was included in the period between the $1^{\text {st }}$ of December and the $28^{\text {th }}$ of February; $2=$ between the $1^{\text {st }}$ of March and the $31^{\text {st }}$ of May; $3=$ between the $1^{\text {st }}$ of June and the $31^{\text {st }}$ of August; $4=$ between the $1^{\text {st }}$ of September and the $30^{\text {th }}$ of November

Table 5 Results of the Stepwise Regression analysis

\begin{tabular}{|c|c|c|c|c|}
\hline Variables & Coefficient & SE coefficient & T-value & $P$-value \\
\hline \multicolumn{5}{|c|}{ Model for $L W G^{a}\left[R^{2}=0.4286 ; C(p)=0.8735\right]$} \\
\hline Intercept & 0.611 & 0.540 & 1.13 & 0.263 \\
\hline Acetate $^{b}$ & 0.108 & 0.033 & 3.27 & 0.002 \\
\hline Average piglet's weight at birth & 0.009 & 0.002 & 5.39 & $<.0001$ \\
\hline \multicolumn{5}{|c|}{ Model for the number of weaned piglets $\left[R^{2}=0.4343 ; C(p)=2.0849\right]$} \\
\hline Intercept & 4.801 & 1.385 & 12.01 & 0.001 \\
\hline cis- Aconitate ${ }^{b}$ & -0.902 & 0.372 & 5.89 & 0.019 \\
\hline Number of alive piglets at birth & 0.584 & 0.10 & 35.05 & $<.0001$ \\
\hline \multicolumn{5}{|c|}{ Model for the number of piglets dead per litter at d $3\left(R^{2}=0.2304 ; C(p)=29.1881\right)$} \\
\hline Intercept & -0.333 & 0.27 & 1.44 & 0.235 \\
\hline Dimethylamine $^{\mathrm{b}}$ & 0.331 & 0.083 & 15.82 & 0.0002 \\
\hline Taurine $^{b}$ & -0.114 & 0.044 & 6.64 & 0.013 \\
\hline
\end{tabular}

aLW stands for the litter body weight gain from birth to d 3

${ }^{b}$ Metabolites concentrations were considered in area arbitrary unit 
Table 6 Results of the GLM analysis

\begin{tabular}{|c|c|c|c|}
\hline Variables & Coefficient & SE & $P$-value \\
\hline \multicolumn{4}{|l|}{ GLM for $L W G^{a}$} \\
\hline Intercept & 0.892 & 0.693 & 0.204 \\
\hline Breed & & & 0.379 \\
\hline$L W^{c}$ & 0 & 0 & \\
\hline$L^{d}$ & -1.072 & 0.934 & \\
\hline$D^{e}$ & 0.352 & 0.821 & \\
\hline Acetate $^{b} \times$ Breed $^{2}$ & & & 0.013 \\
\hline Acetate $^{\mathrm{b}} \times \mathrm{LW}^{\mathrm{c}}$ & 0.094 & 0.052 & \\
\hline Acetate $^{b} \times L^{d}$ & 0.182 & 0.062 & \\
\hline Acetate $^{b} \times D^{e}$ & 0.015 & 0.085 & \\
\hline Average piglet's weight at birth & 0.008 & 0.002 & $<.0001$ \\
\hline \multicolumn{4}{|l|}{ GLM for number of weaned pigs } \\
\hline Intercept & 9.20 & 1.825 & $<.0001$ \\
\hline Breed & & & 0.061 \\
\hline $\mathrm{LW}^{\mathrm{C}}$ & 0 & 0 & \\
\hline$L^{d}$ & -1.822 & 1.534 & \\
\hline$D^{e}$ & -6.743 & 2.85 & \\
\hline cis-Aconitate ${ }^{\mathrm{b}} \times$ Breed & & & 0.008 \\
\hline cis-Aconitate $^{b} \times L^{c}$ & 0.990 & 1.363 & \\
\hline cis-Aconitate $^{b} \times L^{d}$ & -0.293 & 0.596 & \\
\hline cis-Aconitate ${ }^{\mathrm{b}} \times \mathrm{D}^{\mathrm{e}}$ & -1.616 & 0.457 & \\
\hline Number of alive piglets at birth & 0.341 & 0.113 & 0.004 \\
\hline \multicolumn{4}{|c|}{ GLM for Number of dead piglets at d 3} \\
\hline Intercept & -2.226 & 0.764 & 0.005 \\
\hline Breed & & & 0.026 \\
\hline$L W^{c}$ & 0 & 0 & \\
\hline$L^{d}$ & 0.190 & 0.198 & \\
\hline$D^{e}$ & -0.271 & 0.261 & \\
\hline Dimethylamine $e^{b} \times$ Breed & & & 0.001 \\
\hline Dimethylamine $^{b} \times \mathrm{LW}^{c}$ & -0.271 & 0.261 & \\
\hline Dimethylamine $e^{b} \times L^{d}$ & 0.190 & 0.198 & \\
\hline Dimethylamine $^{b} \times D^{e}$ & 0.467 & 0.116 & \\
\hline Taurine ${ }^{b} \times$ Breed & & & 0.036 \\
\hline Taurine $^{\mathrm{b}} \times \mathrm{LW}^{\mathrm{c}}$ & -0.151 & 0.056 & \\
\hline Taurine $^{b} \times L^{d}$ & -0.149 & 0.177 & \\
\hline Taurine $^{b} \times D^{e}$ & 0.174 & 0.207 & \\
\hline Number of alive piglets at birth & 0.127 & 0.058 & 0.035 \\
\hline
\end{tabular}

aWG stands for litter body weight gain from birth to $d 3$ of life

${ }^{\mathrm{b}}$ Metabolites concentrations were considered in area arbitrary unit

'LW stands for Large White

${ }^{\mathrm{d}} \mathrm{L}$ stands for Landrace

${ }^{\mathrm{e} D}$ stands for Duroc

study [26] associated an increased amount of blood creatinine on the $1^{\text {st }}$ day of lactation with lower feeding levels in sows during late gestation period. However, we could not control feed intake in the days before farrowing thus we do not have information regarding its variations according to the season. Therefore, further research is necessary to explain variations of creatine and related compounds in colostrum.

Some of the identified compounds were associated with litter weight gain during the first three days of life and to piglets' survival rates at $\mathrm{d} 3$ and at weaning. In particular, we suppose that the positive effect of acetate on LWG could be linked to the multiple metabolic roles played by this compound, which can be used as energy source by gut mucosa (in particular by colonocytes), as a substrate for the synthesis of cholesterol and long-chain fatty acids [27], and may also stimulate adipogenesis [28]. Additionally, taurine colostrum concentration showed a positive correlation with piglets' survival rate at three days of life. Taurine was already proven to play a critical role in neonatal development, including the development of the central nervous system and other tissues [29, 30]. Furthermore, taurine represents also an important factor in dietary fat absorption. Indeed, this organic compound is involved in conjugating bile acids, which are extremely important for the absorption of fat in infants [31]. Thus, taurine content in sows' colostrum may play an essential role for fat digestion and absorption in piglets, similarly to what was observed in humans [32], showing beneficial effects on piglets' development and energy supply and decreasing the number of dead. As regards the number of dead piglets at three days of life, this performance was positively associated with higher concentration of dimethylamine secreted in colostrum. Dimethylamine is a nitrogenous product, synthesised by bacterial action by the catabolism of trimethylamine or by the metabolism of choline and choline-containing phosphatides. In the literature, dimethylamine was found in sows' serum [33], and in human milk [34], suggesting that dimethylamine can pass from mother's serum to milk (and colostrum). Literature is lacking of studies on the effects of dimethylamine in newborn piglets; anyway it is generally accepted that this compound may have genotoxic [35] and irritant effects on mucosae [36], together with lethargy and coordination disorders in animals [37]. Certainly these results refer to prolonged periods of dimethylamine exposure, but it is also reasonable that sows secreting higher contents of dimethylamine in colostrum coupled with the weakness status of piglets at birth could have led to higher numbers of lethargic piglets, resulting in increased losses during the first three days of life.

Similarly to dimethylamine, also cis-aconitate was negatively associated with piglets' survival capacity from birth to weaning. cis-Aconitate is an intermediate of the tricarboxylic acid (TCA) cycle that regulates the energy metabolism and is the result of the reversible isomerization of citrate to isocitrate via $\mathrm{M}$-aconitase enzyme 
activity [38]. Literature is largely lacking studies about cis-aconitate effects in piglets, but in humans found that increased number of fetal malformation cases was associated with higher levels of cis-aconitate in mothers' serum [39]. Nevertheless, we have not observed foetal malformations in the considered litters. Additionally, another hypothesis can be formulated considering that TCA cycle intermediate metabolites function as metabolic checkpoints for the activation of lipopolysaccharide response genes, such as hypoxia-inducible factor 1-alpha (HIF1A), interleukin 1 beta $(I L 1 B)$ and immune responsive gene 1 (IRG1) [40]. In particular, in M1 macrophages (that are stimulated for a rapid response against inflammation and pathogens) some breaks in Krebs cycle occur: one of them consists in a redirection of citrate towards the production of itaconic acid (whose intermediate is cis-aconitate) [41]. Thus, higher contents of cis-aconitate in colostrum may be associated to the existence of immune response in sows, suggesting that also their litters may have been exposed to the same pathogens, causing more deaths in the first three days of life.

\section{Conclusions}

In conclusion, this study demonstrates that colostrum metabolome is greatly affected by breed and, in particular, Duroc sows showed colostrum compositions unlike any other. This result agrees with the generally accepted view that the differences among Duroc and white coated pig breeds may originate from distinct genetic origins, and consequently, suggests that further genetic studies may help to explain the variations found among breeds in colostrum compositions. From the observation of the results obtained it can be suggested that the different temperatures occurring during the year affect sows' metabolism and, in turn, can also affect colostrum composition. Among the identified metabolites, acetate and taurine showed their positive effects on piglets' performances from birth to day three of age and on piglets' survival rate, while dimethylamine and cis-aconitate exerted a negative influence on the new-borns' capacity to survive. This research represents a preliminary step towards the knowledge of pig colostrum composition and it is one of the first studies focusing on the associations between different swine colostrum compositions and litter performances. Further investigations are needed to extend the identification of the different compounds in swine colostrum and to elucidate their effects on new-borns and on piglets during the post-weaning period. Furthermore, the possible interaction between sows' feeding and microbiota in the modulation of colostrum metabolome deserves further investigations.

\section{Additional file}

Additional file 1: Table S1. The main bins accounting for the spectral differentiation and their relative chemical shift. (DOCX $21 \mathrm{~kb}$ )

\section{Abbreviations \\ ${ }^{1} \mathrm{H}-\mathrm{NMR}$ : Nuclear magnetic resonance with respect to hydrogen-1 nuclei; ANOVA: Analysis of Variance; ATP: Adenosine Triphosphate; D: Duroc; $\mathrm{D}_{2} \mathrm{O}$ : Deuterated Water; EU: European Union; HOD: form of water in a deuterated solvent environment observable among the ${ }^{1} \mathrm{H}-\mathrm{NMR}$ spectroscopy peaks; L: Landrace; LBW: Litter Body Weight; LW: Large White; LWG: Litter Weight Gain; PC: Principal Component; PCA: Principal Components Analysis; PQN: Probabilistic Quotient Normalization; SD: Standard Deviation; SE: Standard Error; SEM: Standard Error of the Mean; TMSP: 3-(trimethylsilyl)-propioniate- 2,2,3,3-d $\mathrm{d}_{4}$; UDP: Uridine diphosphate; UMP: Uridine monophosphate}

\section{Acknowledgements}

We acknowledge Società Agricola La Fortezza s.s. for the samples of sows colostrum and in particular, we gratefully acknowledge the support and assistance of veterinary John Forlenza.

Funding

The research was supported by Italian RFO fundings.

Availability of data and materials

The datasets used and/or analyzed during the current study available from the corresponding author on reasonable request.

\section{Authors' contributions}

PT, PB conceived and designed the experiment. GP and AT carried out the $1 \mathrm{H}-\mathrm{NMR}$ spectroscopy analysis. GP, MZ, DL, AT, FC, VM, RD, LNC, PB and PT analysed, interpreted the data and wrote the manuscript. All authors read and approved the final manuscript.

\section{Ethics approval}

The procedures complied with Italian law pertaining to experimental animals and were approved by the Ethic-Scientific Committee for Experiments on Animals of the University of Bologna, Italy.

\section{Consent for publication}

Not applicable.

\section{Competing interests}

The authors declare that they have no competing interests.

Received: 18 July 2017 Accepted: 17 January 2018

Published online: 07 March 2018

\section{References}

1. Vallet JL, Calderon-Diaz JA, Stalder KJ, Phillips C, Cushman RA, Miles JR, et al. Litter of origin trait effects on gilt development. J Anim Sci. 2016;94:96-105.

2. Devillers N, Le Dividich J, Prunier A. Influence of colostrum intake on piglet survival and immunity. Animal. 2011:5:1605-12.

3. Ferrari CV, Sbardella PE, Bernardi ML, Coutinho ML, Vaz IS, Wentz I, et al. Effect of birth weight and colostrum intake on mortality and performance of piglets after cross-fostering in sows of different parities. Prev Vet Med. 2014;114:259-66.

4. Decaluwé R, Maes D, Wuyts B, Cools A, Piepers S, Janssens GPJ. Piglets' colostrum intake associates with daily weight gain and survival until weaning. Livest Sci. 2014;162:185-92.

5. Noblet J, Dourmad JY, Etienne M, Le Dividich J. Energy metabolism in pregnant sows and newborn pigs. J Anim Sci. 1997;75:2708-14.

6. Rooke JA, Bland IM. The acquisition of passive immunity in the new-born piglet. Livest Prod Sci. 2002;78:13-23.

7. Vallet $J$, Miles JR, Rempel LA. A simple novel measure of passive transfer of maternal immunoglobulin is predictive of preweaning mortality in piglets. Vet J. 2013;195:91-7.

8. Vallet JL, Miles JR, Rempel LA, Nonneman DJ, Lents CA. Relationships between day one piglet serum immunoglobulin immunocrit and subsequent growth, 
puberty attainment, litter size, and lactation performance. J Anim Sci. 2015;93: 2722-9.

9. Ogawa S, Tsukahara T, Imaoka T, Nakanishi N, Ushida K, Inoue R. The effect of colostrum ingestion during the first 24 hours of life on early postnatal development of piglet immune systems. Anim Sci J. 2016;87:1511-5.

10. Schlimme E, Martin D, Meisel H. Nucleosides and Nucleotides: natural bioactive substances in milk and colostrum. Br J Nutr. 2000;84(Suppl 1):S59-68

11. Korhonen HJ. Production and properties of health-promoting proteins and peptides from bovine colostrum and milk. Cell Mol Biol. 2013;59:12-24.

12. He Y, Liu S, Leone S, Newburg DS. Human colostrum oligosaccharides modulate major immunologic pathways of immature human intestine. Mucosal Immunol. 2014;7:1326-39.

13. Foisnet A, Farmer C, David C, Quesnel H. Farrowing induction induces transient alterations in prolactin concentrations and colostrum composition in primiparous sows. J Anim Sci. 2011;89:3048-59.

14. R Core Team. R: a language and environment for statistical Computing 2015. http://www.R-project.org/ . Accessed 11 Jan 2016

15. Dieterle F, Ross A, Schlotterbeck G, Senn H. Probabilistic quotient normalization as robust method to account for dilution of complex biological mixtures. Application in ${ }^{1} \mathrm{H}$ NMR metabonomics. Anal Chem. 2006;78:4281-90.

16. Wu J, Domellöf M, Zivkovic AM, Larsson G, Öhman A, Nording ML. NMRbased metabolite profiling of human milk: a pilot study of methods for investigating compositional changes during lactation. Biochem Biophys Res Commun. 2016;469:626-32.

17. Blasco A, Bindanel JP, Haley CS. Genetic and neonaltal survival. In: Varley MA, editor. The neonatal pig: development and survival. Wallingford: CAB international; 1995. p. 17-37.

18. Sonderman JP, Luebbe JJ. Semen production and fertility issues related to differences in genetic lines of boars. Theriogenology. 2008;70:1380-3.

19. Simmen FA, Whang KY, Simmen RCM, Peterson GA, Bishop MD, Irvin KM. Lactational variation and relationship to postnatal growth of insulin-like growth factor-l in mammary secretions from genetically diverse sows. Domest Anim Endocrinol. 1990;7:199-206

20. Zou S, McLaren DG, Hurley WL. Pig colostrum and milk composition: comparisons between Chinese Meishan and US breeds. Livest Prod Sci. 1992;30:115-27.

21. Park YK, Koo HC, Kim SH, Hwang SY, Jung WK, Kim JM, et al. The analysis of milk components and pathogenic bacteria isolated from bovine raw milk in Korea. J Dairy Sci. 2007;90:5405-14.

22. Linzell JL, Mepham TB. Mammary metabolism in lactating sows: arteriovenous differences of milk precursors and the mammary metabolism of [14C]glucose and [14 Clacetate. Br J Nutr. 1969:23:319-32.

23. Brosnan JT, Brosnan ME. Creatine: endogenous metabolite, dietary, and therapeutic supplement. Annu Rev Nutr. 2007:27:241-61.

24. Lamarre SG, Edison EE, Wijekoon EP, Brosnan ME, Brosnan JT. Suckling rat pups accumulate creatine primarily via de novo synthesis rather than from dam milk. J Nutr. 2010;140:1570-3.

25. Van Niekerk BD, Reid JT, Bensadoun A, Paladines OL. Urinary creatine as an index of body composition. J Nutr. 1963;79:463-73.

26. Decaluwé R, Maes D, Cools A, Wuyts B, De Smet S, Marescau B, et al. Effect of peripartal feeding strategy on colostrum yield and composition in sows. J Anim Sci. 2014a;92:3557-67.

27. Den Besten G, Lange K, Havinga R, Van Dijk TH, Gerding A, Van Eunen K, et al. Gut-derived short-chain fatty acids are vividly assimilated into host carbohydrates and lipids. Am J Physiol Gastrointest Liver Physiol. 2013;305: G900-10.

28. Hong YH, Nishimura Y, Hishikawa D, Tsuzuki H, Miyahara H, Gotoh C, et al. Acetate and propionate short chain fatty acids stimulate adipogenesis via GPCR43. Endocrinology. 2005;146:5092-9.

29. Bryson JM, Jackson SC, Wang H, Hurley WL. Cellular uptake of taurine by lactating porcine mammary tissue. Comp Biochem Physiol - B Biochem Mol Biol. 2001;128:667-73.

30. Aerts L, Van Assche FA. Taurine and taurine-deficiency in the perinatal period. J Perinat Med. 2002;30:281-6.

31. Gaull GE. Taurine in pediatric nutrition: review and update. Pediatrics. 1989; 83:433-42.

32. Guilloteau P, Zabielski R, Hammon HM, Metges CC. Nutritional programming of gastrointestinal tract development. Is the pig a good model for man? Nutr Res Rev. 2010;23:4-22.
33. He Q, Kong X, Wu G, Ren P, Tang H, Hao F, et al. Metabolomic analysis of the response of growing pigs to dietary $L$-arginine supplementation. Amino Acids. 2009;37:199-208.

34. Lichtenberger LM, Gardner JW, Barreto JC, Morriss FH Jr. Evidence for a role of volatile amines in the development of neonatal hypergastrinemia. J Pediatr Gastroenterol Nutr. 1991;13:342-6.

35. Galli A, Paolini M, Lattanzi G, Cantelli-Forti G, Bronzetti G. Genotoxic and biochemical effects of dimethylamine. Mutagenesis. 1993;8:175-8.

36. Fluhr JW, Kelterer D, Fuchs S, Kaatz M, Grieshaber R, Kleesz P, et al. Additive impairment of the barrier function and irritation by biogenic amines and sodium lauryl sulphate: a controlled in vivo tandem irritation study. Skin Pharmacol Physiol. 2005;18:88-97.

37. Dimethylamine. In: The MAK Collection for Occupational Health and Safety. 2012. http:/onlinelibrary.wiley.com/doi/10.1002/3527600418.mb12440e0007/full. Accessed 22 Jan 2018.

38. Cantu D, Schaack J, Patel M. Oxidative inactivation of mitochondrial aconitase results in iron and $\mathrm{H} 2 \mathrm{O} 2$-mediated neurotoxicity in rat primary mesencephalic cultures. PLoS One. 2009;4:e7095.

39. Diaz SO, Pinto J, Graça G, Duarte IF, Barros AS, Galhano E, et al. Metabolic biomarkers of prenatal disorders: an exploratory NMR metabonomics study of second trimester maternal urine and blood plasma. J Proteome Res. 2011;10:3732-42.

40. Papathanassiu AE, Ko JH, Imprialou M, Bagnati M, Srivastava PK, Vu HA, et al. BCAT1 controls metabolic reprogramming in activated human macrophages and is associated with inflammatory diseases. Nat Commun. 2017;8:16040.

41. O'Neill LA. A broken krebs cycle in macrophages. Immunity. 2015;42:393-4.

\section{Submit your next manuscript to BioMed Central and we will help you at every step:}

- We accept pre-submission inquiries

- Our selector tool helps you to find the most relevant journal

- We provide round the clock customer support

- Convenient online submission

- Thorough peer review

- Inclusion in PubMed and all major indexing services

- Maximum visibility for your research

Submit your manuscript at www.biomedcentral.com/submit

) Biomed Central 